\section{ATRIAL NATRIURETIC PEPTIDE RELEASE AT REST AND WITH EXERCISE AFTER CARDIAC TRANSPLANTATION WITH BICAVAL ANASTOMOSES}

Bicaval anastomoses in orthotopic cardiac transplantation offer the advantage of preserving the right atrial geometry. To elucidate the impact of this anastomotic technique on atrial natriuretic peptide plasma levels at rest and with exercise, nine patients were submitted to a symptom-limited supine exercise test. Atrial natriuretic peptide plasma levels in samples obtained from the right atrium were elevated at rest $(274.4 \pm 60.4 \mathrm{pg} / \mathrm{ml})$, at peak exercise $(438.1 \pm 71.7 \mathrm{pg} / \mathrm{ml})$, and thereafter $(328.1 \pm 71.2 \mathrm{pg} / \mathrm{ml})$ with respect to normal reference values of $21 \pm 1 \mathrm{pg} / \mathrm{ml}$ at rest and $92 \pm 14$ at peak exercise. Renin, angiotensin, and aldosterone plasma levels were almost normal and did not indicate any pathologic processes in volume homeoostasis. Right-sided hemodynamic parameters were not correlated with atrial natriuretic peptide secretion. An adverse relationship between cold ischemic time of the donor organ and atrial natriuretic peptide release was found $(r=0.88, p<0.0008$ ), indicating that endocrine cardiocytes are sensitive to prolonged ischemia. Atrial natriuretic peptide release may thus be independent of the surgical approach, and other unique characteristics of the transplanted heart, such as denervation, are more likely to be responsible for elevated atrial natriuretic peptide plasma concentrations after orthotopic heart transplantation. (J THORAC CARDIOVASC SURG 1995; 110:1600-5)

Andres W. Jahnke, MD, ${ }^{*}$ Rainer Leyh, MD, ${ }^{*}$ Alexander Bernhard, PhD, and Hans H. Sievers, $\mathrm{PhD},{ }^{*}$ Kiel, Germany
A trial natriuretic peptide (ANP) is an important determinant in fluid and electrolyte homeostasis, regulating blood pressure and intravascular volume as a functional antagonist to vasopressin and the renin-angiotensin-aldosterone system. ${ }^{1}$ ANP is synthesized and secreted by atrial cardiocytes, which are more frequent in the right atrium than in the left and are most abundant in the atrial appendage. ${ }^{2}$ Excessive ANP plasma levels have been reported in patients with heart failure and also after standard cardiac transplantation. ${ }^{1,3-8}$ The stimulus for the disproportionate increase in plasma ANP level could be the elevated myocardial transmural pres-

From the Clinic of Cardiovascular Surgery, University of Kiel, Kiel, Germany.

Received for publication June 2, 1994.

Accepted for publication April 12, 1995.

Address for reprints: $\mathrm{H} \mathrm{H}$. Sievers, PhD, Medizinische Universität zu Lübeck, Klinik für Herzchirurgie, 23562 Lübeck, Ratzeburger Allee 160.

*Current address: Clinic of Cardiac Surgery, Medical University of Lübeck, Lübeck, Germany.

Copyright $(\mathcal{C} 1995$ by Mosby-Year Book, Inc.

$0022-5223 / 95 \$ 5.00+0 \quad \mathbf{1 2 / 1 / 6 5 6 6 7}$ sure caused by the altered atrial anatomy and concomitantly changed hemodynamics associated with the composite right atrium. ${ }^{1,6,9}$ This standard technique, originally described by Lower and Shumway, ${ }^{10}$ comprises two atrial anastomoses, with a subsequent tissue increase of approximately $25 \%$ of the composite right atrium ${ }^{8}$ and a larger than normal atrial diameter. ${ }^{11}$ In a previous study, ${ }^{11}$ we showed that bicaval anastomoses in heart transplantation, first introduced into clinical practice in $1989,{ }^{12}$ can normalize right atrial dimension compared with the conventional technique. The entire group from that study is included in this report. Bicaval anastomoses in cardiac transplantation provide a unique model of a normally configured right atrium with less secretory atrial tissue. Study of cardiac transplant recipients with bicaval instead of right atrial anastomoses may allow elucidation of the impact of the surgical approach on ANP plasma levels after cardiac transplantation.

\section{Methods}

Patients. Nine consecutive patients with bicaval anastomoses were submitted to a graded, symptom-limited supine exercise test after routine endomyocardial biopsy 
(EMB). The patients had been previously operated on according to a randomized protocol. Informed consent was obtained before the study from every patient. Demographic data of the studied subjects are depicted in Table I. The patients were free of rejection, as proved by EMB, and without clinical signs of congestive heart failure. All cardiac transplant recipients received a conventional triple-drug therapy consisting of cyclosporine (adjusted to a whole blood level of 250 to $300 \mathrm{ng} / \mathrm{ml}$ ), azathioprine (1 to $2 \mathrm{mg} / \mathrm{kg}$ per day), and prednisone $(0.2 \mathrm{mg} / \mathrm{kg}$ per day). Standard induction therapy with anti-T-lymphocyte globulin was done for 4 days. Prednisone was withdrawn as early as clinically possible.

Operative technique. The technique of bicaval anastomoses has been described in detail elsewhere. ${ }^{12}$ In brief, the recipient is cannulated with separate caval cannulas as distally as possible with standard cardiopulmonary bypass and hypothermia of approximately $24^{\circ} \mathrm{C}$. The heart is excised, leaving a $10 \mathrm{~mm}$ atrial cuff at the inferior vena cava and preserving the whole superior vena cava. Trimming is performed with respect to the donor heart size. Concerning the left atrium, only a small cuff combining the pulmonary venous ostia is left in place. The left atrial anastomosis is done with a continuous intraluminal suture of 3-0 Prolene (Ethicon, Inc., Somerville, N.J.). The superior vena cava is sutured with 5-0 Prolene interrupted sutures, and the inferior vena cava is anastomosed with a 4-0 Prolene running suture. The arterial anastomoses are performed conventionally with 3-0 Prolene sutures.

Exercise protocol and collection of blood samples. There was at least 1 hour of rest between EMB and the exercise testing on a supine exercise unit (Siemens $870 \mathrm{~L}$; Siemens ag-Medizinische Technik, Hamburg, Germany). Workload was increased stepwise every 5 minutes by $25 \mathrm{~W}$ until either cardiopulmonary or physical exhaustion. Blood samples for hormone assays were obtained through a triple-lumen thermodilution pulmonary arterial catheter, which was inserted immediately after EMB. Blood samples were drawn from the right atrium at rest, at individual peak exercise, and 10 minutes later. They were collected in chilled tubes containing $10 \mathrm{mg}$ ethylenediaminetetraacetic acid and were stored immediately on dry ice. After completion of the exercise test, the blood samples were centrifuged at $4^{\circ} \mathrm{C}$ for 20 minutes at $2600 \mathrm{rpm}$. The supernatant was stored at $-80^{\circ} \mathrm{C}$ until hormone assay was done, according to the manufacturers' manual (Nichols Institute Diagnostics B.V., Wijchen, The Netherlands). Hemodynamic parameters were measured at each step in triplicate by the use of a Baxter REF 1 thermodilution computer (Baxter Healthcare Corp., Edwards Critical Care, Irvine, Calif.). The mean of three measurements was computed and used for subsequent evaluation.

Hormone assays

$A N P$. ANP was measured by a direct radioimmunoassay for human ANP (Nichols Institute Diagnostics). Free and bound hormone were separated by antibody-polyethylene glycol separation and centrifugation. After decantation of the supernatant, the pellet containing the bound fraction was counted. Quantitation was achieved by delayed addition of the iodinated tracer. Concentrations are expressed in picograms per milliliter after correction for
Table I. Patient characteristics

\begin{tabular}{lc}
\hline & $\begin{array}{c}\text { Bicaval } \\
(n=9)\end{array}$ \\
\hline Age $(\mathrm{yr})$ & $43.6 \pm 5.9$ \\
Height $(\mathrm{cm})$ & $180.2 \pm 2.4$ \\
Weight $(\mathrm{kg})$ & $89.0 \pm 5.0$ \\
Interval $(\mathrm{mo})^{*}$ & $28.0 \pm 4.6$ \\
Donor age $(\mathrm{yr})$ & $41.4 \pm 5.8$ \\
Cold ischemic time (hr) & $2.66 \pm 0.29$ \\
Duration of heart failure $(\mathrm{mo}) \dagger$ & $25.0 \pm 7.8$ \\
Cyclosporine blood level $(\mathrm{ng} / \mathrm{ml})$ & $260 \pm 66$ \\
Creatinine blood level $(\mathrm{mg} / \mathrm{dl})$ & $1.5 \pm 0.2$ \\
\hline
\end{tabular}

"Between heart transplantation and study.

†Before transplantation.

dilution. The normal reference value for ANP at rest is $21 \pm 1 \mathrm{pg} / \mathrm{ml}$, as established in a recently published study. ${ }^{3}$ The reference value for ANP secretion at exercise is $92 \pm$ $14 \mathrm{pg} / \mathrm{ml}$, established in the same study. ${ }^{3}$ To our knowledge, there is no standard for postexercise ANP plasma level in healthy subjects.

Hormone levels were measured to exclude any influence on ANP levels resulting from disorders in the hormonal subsystems of the fluid homeostasis.

Antidiuretic hormone (Vasopressin). Arginine-vasopressin was measured with a double radioimmunoassay (Vasopressin Rapid RIA, RK-AR1, Bühlmann Labaratories Ltd., Schoenenbuch, Switzerland) by means of a modified method previously described by Glick and Kagan. ${ }^{13}$ Plasma samples were extracted with ethanol. Values ranging from 0.8 to $6 \mathrm{pg} / \mathrm{ml}$ were considered normal.

Renin. Plasma renin concentration was measured with a commercially available radioimmunoassay detecting the active renin (Renin-IRMA Pasteur; Laboserv gmbh Diagnostica, Gießen, Germany). Supine normal values range from 10 to $30 \mathrm{pg} / \mathrm{ml}$.

Aldosterone. Plasma aldosterone was measured by the use of a radioimmunoassay without previous extraction. This was achieved according to the concept of solid-phase specific antibody binding (Aldosterone-RIA, solid-phase radioimmunoassay, DPC; Biermann Diagnostics, Bad Nauheim, Germany). Supine normal values range from 12 to $125 \mathrm{pg} / \mathrm{ml}$.

Statistical analysis. All values are expressed as the mean plus or minus the standard error of the mean, as an index of dispersion, unless otherwise specified. Linear regression was applied to determine the relationships between ANP plasma level and hemodynamic parameters. Statistical significance was analyzed with the BehrensFisher $t$ test after evaluation of normal distribution according to the method of David. ${ }^{14}$ A probability value less than 0.05 was considered significant.

\section{Results}

Patient characteristics and work performance. Demographic data and the work performance of the studied subjects is compiled in Table $\mathrm{I}$. The mean workload was $100 \pm 33 \mathrm{~W}$. Renal function, as reflected by creatinine blood level, and cyclosporine 
Table II. Hormonal response at rest, at peak

\begin{tabular}{ccc} 
exercise, and after exercise & \\
& $\begin{array}{r}\text { Bicaval } \\
(n=9)\end{array}$ & Reference value (supine) \\
\hline ANP & & \\
Rest & $274 \pm 60.4$ & $21 \pm 1 \mathrm{pg} / \mathrm{ml}$ (ref. 3)* \\
Peak & $438.1 \pm 71.1$ & $92 \pm 14 \mathrm{pg} / \mathrm{ml}$ (ref. 3)* \\
After & $338.1 \pm 71.2$ & \\
ADH & & \\
Rest & $2.99 \pm 0.73$ & $0.8 \mathrm{pg} / \mathrm{ml} \dagger$ \\
Peak & $2.55 \pm 0.67$ & $6 \mathrm{pg} / \mathrm{ml} \dagger$ \\
After & $3.91 \pm 0.82$ & \\
Renin & & $10 \mathrm{pg} / \mathrm{ml} \dagger$ \\
Rest & $20.44 \pm 2.84$ & $30 \mathrm{pg} / \mathrm{ml} \dagger$ \\
Peak & $25.78 \pm 5.1$ & \\
After & $23.44 \pm 3.86$ & $70 \mathrm{pg} / \mathrm{ml} \dagger$ \\
Aldosterone & & $295 \mathrm{pg} / \mathrm{ml} \dagger$ \\
Rest & $125.4 \pm 22.4$ & \\
Peak & $164.8 \pm 29.2$ & \\
After & $148.1 \pm 34.1$ &
\end{tabular}

"Significant, with $p<0.05$.

$\dagger$ Not significant.

whole blood level were unobtrusive, with no noticeable variation from our standard transplant patients.

Hormonal response. The hormonal changes in blood obtained from the right atrium in response to exercise are presented in Table II. The mean ANP plasma level at rest was $274 \pm 60.4 \mathrm{pg} / \mathrm{ml}$; this was significantly elevated compared with the normal reference value of $21 \pm 1 \mathrm{pg} / \mathrm{ml}(p<0.05){ }^{3}$ Furthermore, we obtained a value of $438.1 \pm 71.7$ $\mathrm{pg} / \mathrm{ml}$ at peak workload. This is significantly elevated compared with the reference value of $92 \pm 14 \mathrm{pg} / \mathrm{ml}$ in normal volunteers $(p<0.05){ }^{3}$ After exercise, the ANP plasma level remained elevated at $338.1 \pm 71.2$ $\mathrm{pg} / \mathrm{ml}$. Because of a lack of normal reference values immediately after exercise, we compared this value with the normal standard of $21 \pm 1 \mathrm{pg} / \mathrm{ml}$ and found it to be significantly elevated $(p<0.05)$. Vasopressin, renin, and aldosterone levels were in the normal range or only slightly elevated (Table II).

Hemodynamic data. Complete hemodynamic data are illustrated in Table III. Right atrial pressure increased 2.1-fold, from $6.4 \pm 1.3 \mathrm{~mm} \mathrm{Hg}$ at rest to 13.6 $\pm 1.8 \mathrm{~mm} \mathrm{Hg}$ at exercise. After exercise, the right atrial pressure $(8.2 \pm 1.3 \mathrm{~mm} \mathrm{Hg})$ returned almost to the resting value. The mean pulmonary arterial pressure, on the other hand, increased from $14.1 \pm 1.5 \mathrm{~mm}$ $\mathrm{Hg}$ to $31.7 \pm 2.7 \mathrm{~mm} \mathrm{Hg}$ at peak exercise, representing a 2.2-fold increase. However, cardiac output $(6.1 \pm 0.5$ $\mathrm{L} / \mathrm{min}$ ) rose only to $11.6 \pm 0.9 \mathrm{~L} / \mathrm{min}$ at peak exercise. The wedge pressure increased from $8.6 \pm 1.3 \mathrm{~mm} \mathrm{Hg}$ to $21.6 \pm 7.8 \mathrm{~mm} \mathrm{Hg}$ at peak exercise. Pulmonary
Table III. Hemodynamic parameters at rest, at peak exercise, and after exercise

\begin{tabular}{lr} 
& Bicaval \\
\hline Right atrial pressure (mm Hg) & \\
Rest & $6.4 \pm 1.3$ \\
Peak & $13.6 \pm 1.8$ \\
After & $8.2 \pm 1.3$ \\
Mean pulmonary artery pressure $\left(\mathrm{mm}^{\mathrm{H}} \mathrm{Hg}\right)$ & \\
Rest & $14.1 \pm 1.5$ \\
Peak & $31.7 \pm 2.7$ \\
After & $13.8 \pm 1.5$ \\
Cardiac output (L/min) & \\
Rest & $6.1 \pm 0.5$ \\
Peak & $11.6 \pm 0.9$ \\
After & $6.4 \pm 0.61$ \\
Wedge pressure (mm Hg) & \\
Rest & $8.6 \pm 1.3$ \\
Peak & $21.6 \pm 7.8$ \\
After & $8.1 \pm 1.1$ \\
Pulmonary vein resistance (dyn $\left.\cdot \mathrm{sec}^{\circ} \mathrm{cm}^{-5}\right)$ & \\
Rest & $74.7 \pm 14.7$ \\
Peak & $84.7 \pm 10.4$ \\
After & $98.8 \pm 19.8$ \\
\hline
\end{tabular}

vascular resistance was uniformly low at rest, at peak exercise, and after exercise (Table III). We did not observe significant correlations by linear regression between ANP plasma levels and hemodynamic variables. An adverse correlation between cold ischemic time and ANP plasma levels obtained from the right atrium was found (Fig. 1).

\section{Discussion}

It is well established that ANP is predominantly synthesized and secreted by endocrine myocytes of the right atrium, ${ }^{4,5}$ but the mechanism of its release is still controversial. ${ }^{15}$ Although ANP is secreted as pro-ANP 1-98, its entire biologic activity is mediated by the metabolite $\alpha$-ANP, ${ }^{15}$ which binds to cellular receptors identified in kidney, adrenal gland, endothelial cells, platelets, and brain. ${ }^{1,16,17}$ The physiologic effect of ANP is the diminution of blood pressure by stimulation of natriuresis, with consequent volume reduction. This is achieved by an attenuated renal vascular tone with consecutive increased glomerular filtration and reduced osmolarity in the kidney. ${ }^{18}$ Because renin secretion is inhibited, angiotensin and aldosterone plasma levels diminish, with a subsequent reduction of vascular tone in all vessels excluding the mesenteric vascular system. ${ }^{19-22}$ A further known effect is the modulation of baroreceptor function, probably transmitted by central sympatholytics. ${ }^{22,23}$ These physiologic effects are important but limited mechanisms in the 


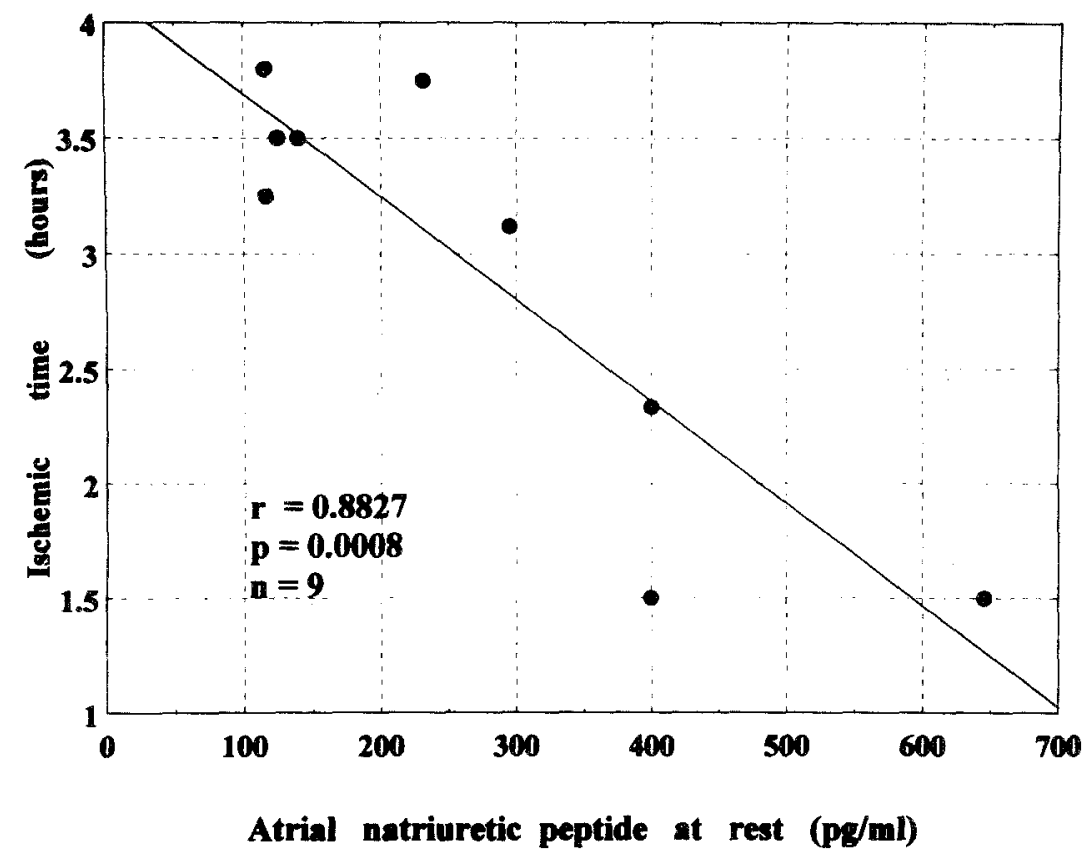

Fig. 1. Correlation between ANP levels obtained from the right atrium at rest and cold ischemic time of the donor organ.

response to the failing heart. Consistently, significantly increased ANP plasma levels have been reported not only in patients with cardiac failure but also, surprisingly, after orthotopic heart transplantation. $^{1,6,9}$

ANP elevation after heart transplantation. The surgical approach itself has been addressed as one responsible factor for increased ANP plasma levels after transplantation. ${ }^{1,6,9}$ Not only do the compound atria of donor and recipient show a cyclic torsion during the cardiac cycle, with increased transmural pressure, ${ }^{24}$ they also result in atrial enlargement, as proved by echocardiography. ${ }^{7,11,12,24}$ A larger diameter may result in a higher transmural pressure, according to the law of Laplace, and thus be responsible for increased ANP secretion. A further important aspect may be the additional amount of atrial tissue associated with atrial anastomoses. ${ }^{8}$ If ANP is reduced by right atrial appendectomy, as proven clinically in human beings ${ }^{25}$ and experimentally in dogs, ${ }^{26}$ it might be postulated that additional atrial tissue as an adjunct to altered atrial configuration increases ANP secretion after cardiac replacement. Because we showed in a previous study ${ }^{11}$ that right atrial dimension is significantly reduced and normal after bicaval anastomoses, we believe that this patient population can serve as a model to study the impact of the surgical approach on ANP release after cardiac replacement.

On the basis of these observations, we hypothesized that patients with bicaval anastomoses and subsequent reduced atrial dimensions and tissue would have normal ANP plasma levels. Our findings do not support this assumption, however; we found elevated ANP concentrations in the studied group compared with normal reference values, as depicted in Table II $(274 \pm 60.4 \mathrm{pg} / \mathrm{ml}$ versus $21 \pm 1 \mathrm{pg} / \mathrm{ml}$, $p<0.05)$. The elevations of the ANP concentrations were comparable to those mentioned in patients after standard atrial heart transplantation., $1,6-8$ Furthermore, a comparison of these data with additional data from patients with standard orthotopic heart transplantation $(n=5)$ who were also examined in this study clearly shows that patients with bicaval anastomoses do not have decreased ANP release $(274 \pm 60.4 \mathrm{pg} / \mathrm{ml}$ bicaval versus $226 \pm 69.2$ $\mathrm{pg} / \mathrm{ml}$ atrial). The elevated ANP secretion after cardiac transplantation may therefore be caused by a more complex multifactorial process rather than simply a larger atrial tissue dimension or mass. Despite the lack of significant correlations between right atrial filling pressures and ANP plasma levels in this study, an association between right heart afterload and ANP secretion may still be possible, as 
other investigators have proposed. ${ }^{1,6,9}$ It cannot, however, be deduced from our data and limited patient number.

Total denervation and ANP release. This study gives clinical support to experimental findings in $\operatorname{dog}^{27}$ and rats ${ }^{28}$ that totally denervated hearts are capable of excessive ANP secretion, because the use of bicaval anastomoses results in total denervation as a result of the total extirpation of the recipient's heart, in contrast to the standard technique in which innervated remnants of the right atrium remain. It has been proposed that the sympathetic system has a suppressive effect on ANP synthesis and that sympathetic denervation thus increases ANP release. ${ }^{27} \mathrm{~A}$ hypersensitivity of ANP-synthesizing cells to circulating catecholamines may be a further possible mechanism. ${ }^{7}$ Taking these and our results into account, one is tempted to assume that the altered innervation of the transplanted heart may play the major role in increased ANP secretion after heart replacement.

Cold ischemic time and ANP. Interestingly, a moderate and adverse correlation $(r=0.88)$ between ANP plasma level and cold ischemic time of the donor organ is evident (Fig. 1). Although we do not have a sufficient explanation at hand, this may indicate that ANP-secreting myocytes are sensitive to prolonged ischemic events. Further investigations including studies of myocardial contractile function are needed to elucidate the impact of ischemic time on different cardiac cell populations.

Study limitations. The most important limitation is the small sample size. Our results have to be interpreted carefully and need further investigations with larger patient numbers to fully elucidate the impact of the anastomotic technique on ANP secretion.

Conclusion. This study shows that the bicaval technique of cardiac transplantation, which, preserves the right atrial geometry, does not result in normal ANP release as long as $11.4 \pm 2.3$ months after operation. Whether the marked and excessive increase of ANP is related to denervation or to ischemic time remains to be evaluated in a larger series of patients.

\section{REFERENCES}

1. Mertes PM, de Talance N, Mattei MF, Burlet C, Villemot JP, Boulange M. Short-term effects of human orthotopic heart transplantation on hormones regulating fluid and electrolyte balance. J Heart Lung Transplant 1991;10:56-62.
2. Garcia R, Cantin M, Thibault G. Role of right and left atria in natriuresis and atrial natriuretic factor release during blood volume changes in the conscious rat. Circ Res 1987;61:99-106.

3. Starling RC, O'Dorisio TM, Malarkey WB, Murray KD, Myerowitz PD, Cody RC. Preserved atrial natriuretic peptide secretory function after cardiac transplantation. Am J Cardiol 1991;68:237-41.

4. Burnett JC, Kao PC, Hu DC, et al. Atrial natriuretic peptide elevation in congestive heart failure in the human. Science 1986;231:1145-7.

5. Raine AEG, Erne $P$, Bürgiser E, et al. Atrial natriuretic peptide and atrial pressure in patients with congestive heart failure. N Engl J Med 1986;315: 533-7.

6. Wilkins MR, Gammage MD, Lewis HM, Tan LB. Raised concentrations of plasma atrial natriuretic peptides in cardiac transplant recipients [Letter]. BMJ [Clin Res] 1987;294:122.

7. Brouwer RM, Wenting GJ, Zijlstra F, et al. Atrial wall stress rather than pressure per se might be responsible for the increased secretion of ANF after heart transplantation. J Hypertens 1988;6:330-2.

8. Singer DRJ, Buckley MG, MacGregor GA, Khaghani A, Banner NR, Yacoub MH. Raised concentrations of plasma atrial natriuretic peptides in cardiac trans. plant recipients. BMJ 1986;293:1391-2.

9. Riddervold F, Forslund T, Endresen K, Simonsen S, Talseth T, Fyhrquist F. Hormonal changes during tilt and atrial pacing in heart transplant patients. Transplant Proc 1990;22:191-4.

10. Lower RR, Shumway NE. Studies on orthotopic homotransplantation of the canine heart. Surg Forum 1960;11:18-9.

11. Sievers HH, Leyh R, Jahnke AW, et al. Bicaval versus atrial anastomoses in cardiac transplantation: right atrial dimension and tricuspid valve function at rest and during exercise up to thirty six months after transplantation. J Thorac CardiovasC SuRg 1994;108:780-4.

12. Sievers HH, Weynand M, Kraatz EG, Bernhard A. An alternative technique for orthotopic cardiac transplantation, with preservation of the normal anatomy of the right atrium. Thorac Cardiovase Surg 1991;39:70-2.

13. Glick SM, Kagan A. Radioimmunoassay of arginine vasopressin. In: Jaffe BM, Behrmann HR, eds. Methods of hormone radioimmunoassays. New York: Academic Press, 1979.

14. David HA, Hartley HO, Pearson ES. The distribution of the ratio, in a single normal sample, of range to standard deviation. Biometrika 1954;41:482-93.

15. Newman TM, Severs NJ. Arrested exocytosis of atrial secretory granules. J Mol Cell Cardiol 1990;22:771-86.

16. Schiffrin EL. Regulation of receptors for ANP in the rat and human. Cardiovasc Drugs Therapy 1988;2: 493-500.

17. Chinkers M, Garbers DL, Chang MS, et al. A mem- 
brane form of guanylate cyclase is an atrial natriuretic peptide receptor. Nature 1989;338:78-83.

18. Delaney VB, Bourke E. The interrelationship of heart and kidney disease. In: Hurst JW, Schlant RC, eds. The heart. New York: McGraw-Hill, 1990:1543-56.

19. Atlas S, Maack T. Effects of atrial natriuretic peptide on the kidney and the renin-angiotensin-aldosteron system. Endocrinol Metab Clin North Am 1087;16:107-12.

20. Rosenthal AD, Moran M, Herrmann HC. Coronary hemodynamic effects of ANP in humans. J Am Coll Cardiol 1990;16:1107-13.

21. Woods RL, Anderson WP. ANP infusion causes vasoconstriction after autonomic blockade in conscious dogs. Am J Physiol 1990;259:813-22.

22. Volpe $\mathrm{M}$, Lembo $\mathrm{G}$, Condorelli $\mathrm{G}$, et al. Converting enzyme inhibition prevents the effects of ANP on baroreflex responses in humans. Circulation 1990;82: 1214-21.

23. Floras JS. Sympathicoinhibitory effects of ANF in normal humans. Circulation 1990;81:1860-73.

24. Angermann CE, Spes CH, Tammen A, et al. Ana- tomic characteristics and valvular function of the transplanted heart: transthoracic versus transoesophageal echocardiographic findings. J Heart Transplant 1990;9:331-8.

25. Nishimura $K$, Saito $Y$, Hidaka $T$, et al. Does atrial appendectomy aggravate secretory function of atrial natriuretic peptide? J ThORAC CARDIOVASC SURG 1991;101:502-8.

26. Omari BO, Nelson RJ, Robertson JM. Effect of right atrial appendectomy on the release of atrial natriuretic hormone. J Thorac Cardiovasc Surg 1991; 102:272-9.

27. Goetz KC, Wang BC, Geer PG, Leadley RJ, Reinhard HW. Atrial stretch increases sodium excretion independendly of release of atrial peptide. Am J Physiol 1986;250:R946-50.

28. Albino-Teixeira A, Polónia JJ, Azevedo I. Sympathetic denervation causes atrial natriuretic peptide-storing granules to appear in the ventricular myocardium of the rat. Naunyn Schmiedebergs Arch Pharmacol 1990;342: 241-4.

\section{ON THE MOVE?}

Send us your new address at least six weeks ahead

Don't miss a single issue of the journal! To ensure prompt service when you change your address, please photocopy and complete the form below.

Please send your change of address notification at least six weeks before your move to ensure continued service. We regret we cannot guarantee replacement of issues missed due to late notification.

JOURNAL TITLE:

Fill in the title of the joumal here.

\section{OLD ADDRESS:}

Affix the address label from a recent issue of the journal here.

\section{NEW ADDRESS:}

Clearly print your new address here.

Name

Address

City/State/ZIP
COPY AND MAIL THIS FORM TO:

Journal Subscription Services

Mosby-Year Book, Inc.

11830 Westline Industrial Dr.

St. Louis, MO 63146-3318
OR FAX TO:

314-432-1158

N/Mosby
OR PHONE:

1-800-453-4351

Outside the U.S., call

314-453-4351 